\title{
REVIEW
}

\section{The role of thyroid hormones in depression}

\author{
Carsten Kirkegaard and Jens Faber \\ Department of Internal Medicine F, Hillerød Sygehus, and Department of Endocrinology E, Frederiksberg Hospital, Denmark \\ (Correspondence should be addressed to C Kirkegaard, Department of Internal Medicine F, Hillerød Sygehus, DK-340O Hillerød, Denmark)
}

\section{Introduction}

During the last 30 years a huge number of scientific articles have appeared on the subject of relationships between psychiatric disease and thyroid hormones. These studies have demonstrated the presence of numerous changes in the hypothalamo-pituitarythyroid (HPT) axis, mainly in patients with depression, but also in patients with other psychiatric diseases. Simultaneously, many studies have been published on the possible therapeutic effects in depression of the hormones involved in the HPT axis.

Despite great efforts to standardize the classification of depression, this is still a less well-defined disease. possibly including several subtypes with different pathogenesis and biochemical abnormalities. Furthermore the classification has changed over time, making it difficult to interpret previously published data. The most accepted classifications are the DSM-IV and ICD-10. These cover a spectrum from minor depression (neurotic depression) through major depression to melancholic (endogenous and psychotic) depression. Furthermore major and melancholic depressions are divided into uniand bipolar depressions, the latter also demonstrating episodes of mania. Rapid cycling bipolar psychosis is a subgroup of the bipolar depression, demonstrating four or more episodes in any year of observation.

The present review focuses on the concentrations of hormones of the HPT-axis seen in uni- and bipolar depression, their relation to relapse after antidepressive treatment, and a survey of therapeutic trials with thyrotropin-releasing hormone (TRH), thyroid-stimulating hormone (TSH) and thyroid hormones, as well as the effect of the various drugs used in depression on the HPT-axis. The hypothesis is put forward that the changes seen in the HPT-axis during depression might be explained by cerebral serotonin deficiency, and that tri-iodothyronine $\left(\mathrm{T}_{3}\right)$ treatment, to some degree, can revert this deficiency.

\section{Iodothyronines in depression}

An overall picture of thyroid-related disturbances seen in depression is given in Table 1 .

\section{Thyroxine $\left(\mathrm{T}_{4}\right)$}

Serum $\mathrm{T}_{4}$ levels, both total and non-protein-bound (free), are consistently found as normal to increased in groups of depressed patients (reviewed in 1, 2), approximately $25 \%$ of the patients having levels above the reference range. The different findings might be explained by the different severity of depression among the patients studied, since some studies have found a correlation between the severity of depression and serum $\mathrm{T}_{4}$ levels (2). An additional explanation might be that the depressed patient is often in a state of semistarvation, and thus may present changes in the HPTaxis similar to those seen in patients with nonthyroidal somatic illness, elevated serum $\mathrm{T}_{4}$ and $3,3^{\prime}, 5^{\prime}$-triiodothyronine $\left(\mathrm{rT}_{3}\right)$, and reduced serum $\mathrm{T}_{3}$.

Turnover studies using radiolabeled $\mathrm{T}_{4}$ in a small group of depressed patients have demonstrated that also the daily production rate $(\mathrm{PR})$ of $\mathrm{T}_{4}$ is significantly increased, by $30 \%$ (3). This finding contrasts with the unaltered $\mathrm{T}_{4}$ PR found in groups of patients with different nonthyroidal illnesses (4). These studies used a noncompartmental kinetic approach for the evaluation of PRs. This method correctly estimates the PR of $\mathrm{T}_{4}$. Increased $\mathrm{PR}$ of $\mathrm{T}_{4}$ in depressed patients thus suggests that the thyroid gland is stimulated abnormally in the depressed patient.

The concentration of free $\mathrm{T}_{4}$ in cerebrospinal fluid (CSF) seems relatively increased during depression, since recovery is followed by a reduction (5). The ratio between CSF and serum free $\mathrm{T}_{4}$ levels has been found to be $0 \cdot 6$, both before and after recovery of depression due to electro-convulsive treatment (ECT) (5). This suggests that $\mathrm{CSF}_{4}$ concentrations follow systemic levels, and that transport of $\mathrm{T}_{4}$ into CSF is restricted. An alternative explanation is that $\mathrm{T}_{4}$ is taken up directly into brain tissues, and partly undergoes deiodination, thus yielding less $\mathrm{T}_{4}$ into the CSF.

\section{$\boldsymbol{T}_{3}$}

Serum $\mathrm{T}_{3}$ levels in depressed patients are often found normal, but several studies have found reduced levels, typically in more severely depressed patients $(1,2)$. Serum $\mathrm{T}_{3}$ levels are influenced by numerous factors which all may be present in the depressed patient: starvation, concomitant somatic illness and medication, and changes (increase) in cortisol levels. When present these factors all tend to decrease serum $\mathrm{T}_{3}$ levels $(4,6)$. This makes interpretation of serum $\mathrm{T}_{3}$ concentrations difficult. Serum free $\mathrm{T}_{3}$ levels have been found both 
Table 1 Changes in total and free serum concentrations, CSF concentrations, and production rates of various hormones in patients with depression. Relevant references are given in parentheses.

\begin{tabular}{|c|c|c|c|c|}
\hline & Total serum & Free serum & CSF & Production rate \\
\hline $\mathrm{T}_{4}$ & Increased $(1,2)$ & Increased $(1,2)$ & Increased (5) & Increased (3) \\
\hline$T_{3}$ & Unaltered $(1,2)$ & Unaltered $(2,9)$ & - & Unaltered (3) \\
\hline & Decreased $(1,2)$ & Decreased (2) & & \\
\hline $\mathrm{rT}_{3}$ & Increased $(2,11)$ & Unaltered (2) & Increased $(5,12)$ & - \\
\hline & Unaltered $(5,9)$ & Increased $(5,11)$ & & \\
\hline TSH & $\begin{array}{l}\text { Decreased, but elevated in } \\
\text { comparison to } T_{4} \text { production } \\
(1,3,13-17) \text {. In TCA- } \\
\text { resistance and RCBP, increased } \\
\text { TSH possible }(27-30)\end{array}$ & - & - & - \\
\hline$\Delta \max T S H$ & $\begin{array}{l}\text { Decreased }(1,2,13) \\
\text { Increased }(27-30)\end{array}$ & - & - & - \\
\hline $\mathrm{TRH}$ & - & - & $\begin{array}{l}\text { Increased }(20,21) \\
\text { Unaltered }(22)\end{array}$ & - \\
\hline Somatostatin & - & - & Decreased (24-26) & - \\
\hline
\end{tabular}

$\mathrm{TCA}=$ tricyclic antidepressants; $\mathrm{RCBP}=$ rapid cycling of bipolar psychosis.

normal and reduced (2). However, methods for the measurement of free $\mathrm{T}_{3}$ in serum often give spurious, mainly reduced levels, in diseased patients (7). Ultrafiltration seems the method of choice $(7,8)$, and using this technique we have found unaltered free $\mathrm{T}_{3}$ levels in depression (9). The daily PR of $\mathrm{T}_{3}$ in unmedicated, moderately depressed patients has been studied using tracer turnover techniques, and $\mathrm{T}_{3} \mathrm{PR}$ was found normal (3). This was quite different from patients with various nonthyroidal illnesses, in whom a $40 \%$ reduction in $\mathrm{T}_{3} \mathrm{PR}$ has been demonstrated (4). The combination of an increased $\mathrm{T}_{4} \mathrm{PR}$ and an unaltered $\mathrm{T}_{3} \mathrm{PR}$ in depression suggests a reduced deiodination of $\mathrm{T}_{4}$ into $\mathrm{T}_{3}$, as also seen in nonthyroidal illness, but with more substrate $\left(\mathrm{T}_{4}\right)$ availability than in somatic nonthyroidal illnesses. However, correct interpretation of noncompartmental tracer studies is based on the assumption that the tracer injected is distributed freely into all tissue compartments (4). If anything, some degree of underestimation of $\mathrm{T}_{3} \mathrm{PR}$ might take place when performing $\mathrm{T}_{3}$ kinetics in humans (4), but conflicting results are available on this issue (10).

The reduced conversion of $\mathrm{T}_{4}$ into $\mathrm{T}_{3}$ seen during depression (3) might be due to reduced deiodination enzyme activity. However, in which compartment of the human body this takes place is at present unknown. This could in theory be the brain, but unfortunately we are not aware of any data on intracerebral $\mathrm{T}_{3}$ content or CSF levels of $\mathrm{T}_{3}$ in depression.

\section{$r T_{3}$}

Changes in serum total as well as free $\mathrm{rT}_{3}$ levels in depression seem to follow those seen for serum total and free $\mathrm{T}_{4}$, respectively $(2,5,11)$.

CSF levels of $\mathrm{rT}_{3}$ have been studied in different types of depression, and have been found highest in the endogenous type (12). Similar to changes in serum, CSF free $\mathrm{rT}_{3}$ concentrations seem to follow CSF free $\mathrm{T}_{4}$ levels (5), but the ratio of CSF to serum free $\mathrm{rT}_{3}$ has been found to be approximately 26 , which is quite different from that of $\mathrm{T}_{4}(0.6)$ (5). This ratio for $\mathrm{rT}_{3}$ did not change after recovery from the depression, and this suggests that intracerebral concentration of $\mathrm{rT}_{3}$ is high in humans, and that $\mathrm{rT}_{3}$ in brain is mainly derived from local production from $\mathrm{T}_{4}$. This enzymatic production seems not changed in depression, and this argues against $\mathrm{rT}_{3}$ as a pathogenic factor in depression.

\section{TSH in depression}

Previously, changes in circulating levels of TSH in depressed patients were evaluated using the TSH response to intravenous TRH, due to lack of sufficiently sensitive TSH assays. The response in TSH has usually been evaluated as the peak value minus basal TSH $(\Delta \mathrm{TSH})$. Normal $\Delta \mathrm{TSH}$ to $200 \mu \mathrm{g}$ TRH i.v. is typically $2-$ $16 \mathrm{mU} / \mathrm{l}$. Patients with depression, as a group, have reduced $\Delta \mathrm{TSH}$, and approximately $25 \%$ have $\Delta \mathrm{TSH}$ below $2 \mathrm{mU} / \mathrm{l}$ in endogenous (melancholic) depression (1). Using newer, and more sensitive TSH methods, basal TSH values correlate closely to peak TSH as well as $\Delta$ TSH (13-15). According to this, depressed patients seem to have some degree of reduced basal serum TSH, but within the normal range $(13,15)$. Basal as well as $\Delta$ TSH using a sensitive TSH assay have been studied in various types of depression, and those patients with endogenous depression had the lowest levels of both basal TSH and $\Delta$ TSH (13), $\Delta$ TSH being a mean of $3.6 \mathrm{mU} / \mathrm{l}$

The diurnal variation of serum TSH is, in healthy man, associated with a surge in TSH around midnight. In untreated depression this diurnal variation seems attenuated (16). After complete recovery from depression the diurnal TSH variation seemed to be re-established, but 
no or incomplete recovery still harbored an attenuated diurnal variation (17).

In one study the interrelation between serum TSH concentrations and the daily production of $\mathrm{T}_{4}$ and $\mathrm{T}_{3}$ in endogenous depression was evaluated (3). Six depressed patients were compared with seven subjects with $\mathrm{L}_{-} \mathrm{T}_{4^{-}}$ treated hypothyroidism. These two groups had quite similar $\mathrm{T}_{4}$ and $\mathrm{T}_{3} \mathrm{PRs}$, both having an equal $\mathrm{T}_{4} \mathrm{PR} / \mathrm{T}_{3}$ PR ratio. Serum TSH level using a sensitive assay was a median $0.11 \mathrm{mU} / \mathrm{l}$ among $\mathrm{L}_{-} \mathrm{T}_{4}$-treated hypothyroid subjects, but $0.90 \mathrm{mU} / \mathrm{l}$ in depressed patients, significantly higher than in the $\mathrm{L}_{-} \mathrm{T}_{4}$-treated hypothyroid group (3). This suggests an inappropriate secretion of TSH (in relation to the elevated thyroidal production of $\mathrm{T}_{4}$ ) in patients with endogenous depression, compatible with some degree of central over-stimulation of the thyroid in the untreated depressed state.

The apparent paradox that serum TSH levels are found slightly decreased among depressed patients, and our statement of inappropriately elevated serum TSH levels in comparison to daily production of $\mathrm{T}_{4}$ and $\mathrm{T}_{3}$ (3), can be compared with the situation of chronic TRH stimulation (by oral administration) in man. In this experimental setting, TRH induced an initial increase in serum TSH, whereas later, at the time when serum $\mathrm{T}_{4}$ and $\mathrm{T}_{3}$ began to increase, serum TSH levels were normalized and were unable to respond to repeated TRH stimulation $(18,19)$. Thus chronic stimulation with TRH in man can provoke a pattern in serum levels of $\mathrm{TSH}, \mathrm{T}_{4}$ and $\mathrm{T}_{3}$ similar to those seen in the depressed patient.

Chronic stimulation of the thyrothrophs in the pituitary during depression might be caused by TRH, since TRH levels have been found elevated in CSF in two studies (in total 31 patients) $(20,21)$, although normal levels were found in a third study including 17 patients (22). Serum TSH levels are also influenced by somatostatin, which inhibits the TSH release from the pituitary (23). Three studies have found that the CSF concentration of somatostatin is reduced during depression (24-26). This might contribute to an increase in serum TSH levels.

Two subgroups of the depression syndrome seem to present with a different pattern in the HPT-axis. One group consists of patients with bipolar depression $(27,28)$, and another group of patients is characterized by a depression resistant to treatment with tricyclic antidepressants (TCA) $(29,30)$. Both groups have a tendency towards slightly elevated basal serum TSH levels (approximately 20\% have levels above the upper normal reference range), or exaggerated TSH response to TRH stimulation. These changes seem independent of previous or ongoing lithium treatment, and probably reflect some degree of thyroid insufficiency. Immunological mechanisms seem to play a role, since patients with bipolar depression have increased frequency of sera positive for antithyroid peroxidase (anti-TPO) antibodies (28). Whether this is an epiphenomenon to bipolar depression, or might be considered as one of several pathogenic factors, is at present unknown. Interestingly, postpartum changes in mood seem to be associated with the presence of anti-TPO antibodies and thyroid dysfunction (31). Thyroid hormone substitution might therefore be of potential benefit in alleviating depressive symptoms in the puerperal period. A preliminary study, in which $\mathrm{L}_{-} \mathrm{T}_{4}$ was administered immediately after delivery, in fact resulted in reduced depression score among the $\mathrm{L}_{-} \mathrm{T}_{4}$-treated women compared with placebo treatment (32).

\section{Predictive value of changes of $\Delta$ TSH}

Another interesting aspect of the TSH response to TRH is the possible predictive value of the changes before and after antidepressive treatment. It is a typical clinical finding that depressed patients, after recovery following ECT, demonstrate a high frequency of early relapse, typically within 6 months, if not treated prophylactically with antidepressive medication. We have repeatedly demonstrated that those patients with early relapse of endogenous depression have not normalized their reduced TSH response to TRH, despite clinical recovery. This has been demonstrated after treatment with ECT as well as sleep deprivation (i.e. nonpharmacological treatment modalities) $(1,33,34)$. More than $80 \%$ of those patients with early relapse did not change their maximal TSH response to TRH ( $\Delta$ max TSH). An unchanged $\Delta \max$ TSH was defined as post-treatment $\Delta \max$ TSH minus pre-treatment $\Delta \max \mathrm{TSH}(\Delta \Delta \max \mathrm{TSH})$ less than $2 \mathrm{mU} / \mathrm{l}$. By contrast more than $80 \%$ of those patients who remained clinically cured for more than 6 months had a $\Delta \Delta$ max TSH exceeding $2 \mathrm{mU} / \mathrm{l}$ (1). Serum $\mathrm{T}_{4}$ as well as free $\mathrm{T}_{4}$ levels remained elevated in those patients with early relapse and continued reduced $\Delta \max$ TSH (9). Thus a continued disturbance of the HPT-axis despite clinical improvement of endogenous depression suggests that the patient is not clinically cured. However, other studies in patients treated with antidepressive medication, rather than nonpharmacological treatment, have been unable to confirm these results (2).

In a small group of patients treated with amitriptyline we confirmed this lack of predictive value of the TRH test (33). Thus it is possible that the use of antidepressive medication might interfere with the HPT-axis on multiple sites, thus blurring the finding seen in the unmedicated, clinically cured patient. Alternatively, in the studies using TCA, the TRH tests have been performed with intervals too long to maintain a stable $\Delta \mathrm{TSH}$ in patients not cured of depression.

\section{Relationships between depression and thyroid hormones - a hypothesis}

The pathogenesis of endogenous depression is not known, and is most probably multifactorial. The 


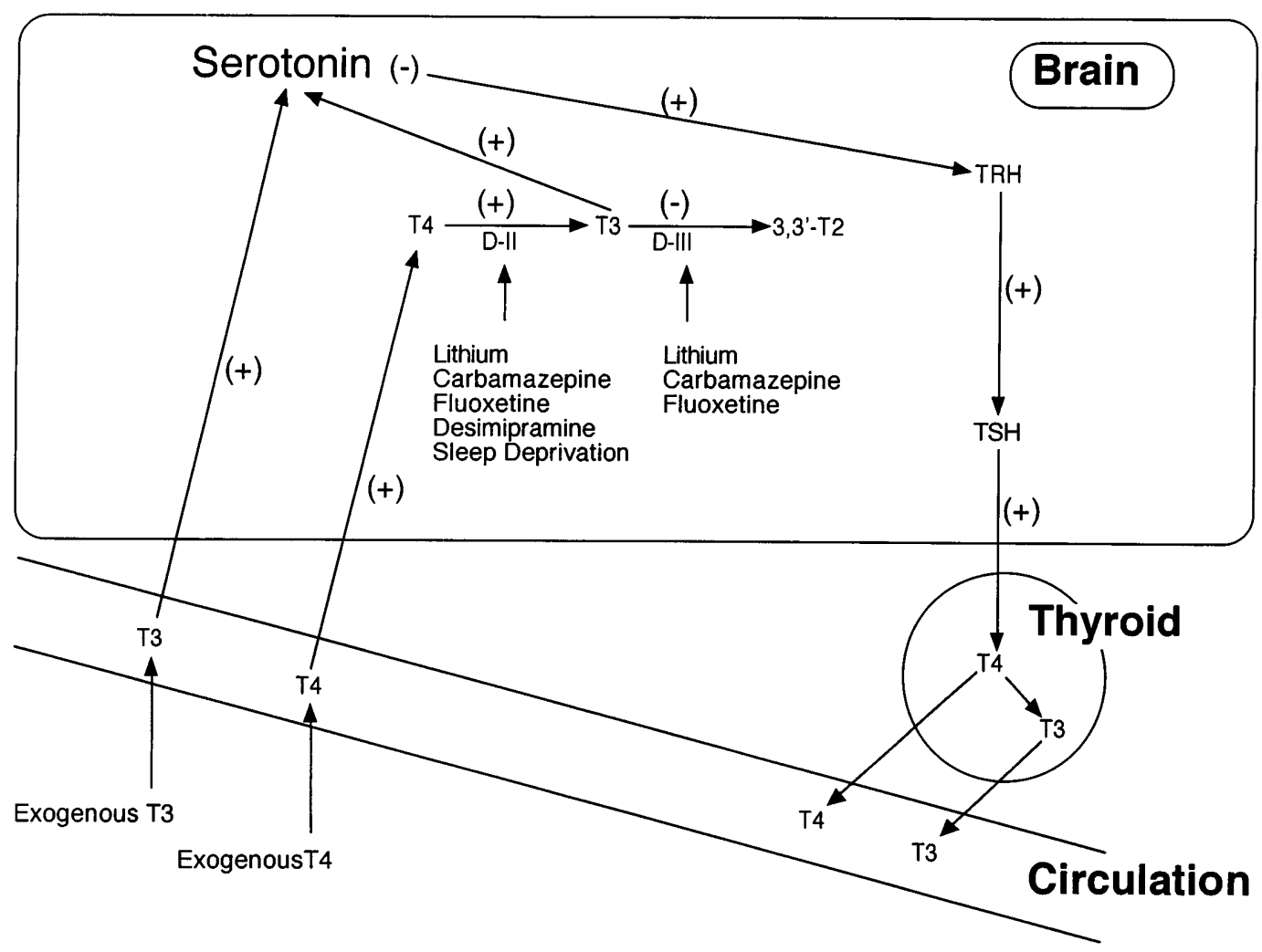

Figure 1 Decreased brain serotonin levels (serotonin (-)) activate (indicated by $(+)$ ) the HPT-axis, and increased $\mathrm{T}_{3}$ (by endogenous as well as exogenous sources) increases brain serotonin levels (feed-back) - a hypothesis. D-II and D-III refer to iodothyronine deiodinases type II and III, respectively. 3,3'-T2: 3,3'-diiodothyronine.

currently favored hypothesis is that a lack of serotonin in the brain has a central role (35). This hypothesis has generated the development of effective antidepressive drugs belonging to the group of serotonin re-uptake inhibitors. TRH seems under a constant inhibition by serotonin, and reduced intracerebral serotonin concentration will lead to increased TRH concentrations in brain tissue (reviewed in 23) (Fig. 1). As a consequence, TSH secretion will be stimulated. In addition CSF levels of somatostatin are reduced in depression. Since TSH secretion is under a constant inhibition of somatostatin (23), the consequence might be a further stimulated TSH secretion. Increased TSH levels result in enhanced thyroidal production of $\mathrm{T}_{4}$ and $\mathrm{T}_{3}$. Due to the thyroidpituitary feedback, increased $\mathrm{T}_{4}$ and $\mathrm{T}_{3}$ levels tend to reduce serum TSH levels, reaching a new steady state usually within the normal range. The new TSH levels are, however, inappropriately elevated in relation to the increased $\mathrm{T}_{4}$ production (3).

Acute as well as chronic $\mathrm{T}_{3}$ treatment has been shown to increase the serotonin levels in the cerebral cortex of rats (36). In man, plasma serotonin levels correlate positively with $\mathrm{T}_{3}$ concentrations $(37,38)$, and treatment of hyperthyroidism results in a reduction in serum serotonin levels (37). Brain serotonin levels in rats seem similarly affected, i.e. synthesis is reduced in hypothyroidism (39) and increased in hyperthyroidism $(40,41)$.

Thus the findings that reduced intracerebral serotonin concentrations lead to increased TRH and thereby to increased thyroid hormone levels, and that increased $\mathrm{T}_{3}$ levels lead to an increase in brain serotonin, seem to constitute a classical feedback mechanism relevant to alleviation of depression.

Intracerebral $\mathrm{T}_{3}$ seems mainly a result of local production by deiodination of $\mathrm{T}_{4}$. In general, at least three deiodinating enzymes seem capable of affecting the turnover of $\mathrm{T}_{4}$ and $\mathrm{T}_{3}$ (reviewed in 42). The type-I deiodinase (D-I) results in both inner (5-) and outer (5'-) ring deiodination, mainly of $\mathrm{T}_{4}$, which thereby provides a circulating source of $\mathrm{T}_{3}$ to the peripheral tissues. The type-II deiodinase (D-II) results in outer (5'-) ring deiodination, mainly of $\mathrm{T}_{4}$. This enzyme functions to regulate intracellular $T_{3}$ levels in those tissues where $T_{3}$ is most critical, such as brain and pituitary. In line with this, the enzyme activity is increased in hypothyroidism and reduced in hyperthyroidism. The type-III (D-III) enzyme results in inner (5-) ring deiodination, of both $\mathrm{T}_{4}$ into $\mathrm{rT}_{3}$, and $\mathrm{T}_{3}$ into $3,3^{\prime}-\mathrm{T} 2$, and, in contrast to the D-II, but similar to D-I, its activity is increased in hyperthyroidism and decreased in hypothyroidism. Whereas all three enzymes are present in rat brain 
(42), human brain tissues seem to contain only D-II and D-III enzymes (43). The properties of the D-II and D-III enzymes in rat and human tissues seem quite similar (43). Thus D-II activity increases $\mathrm{T}_{3}$ production in brain and pituitary, and consequently also the local production of serotonin. In addition, D-III activity might be expected to decrease the local concentration of $\mathrm{T}_{3}$ and indirectly of serotonin in brain tissues.

Studies of the influence of several known antidepressive drugs on rat D-II and D-III enzyme activities have revealed a similar pattern: lithium (44), des-imipramine (45), carbamazepine (46), and fluoxetine (47) have been shown to enhance the activity of the D-II enzyme resulting in increased local $\mathrm{T}_{3}$ concentrations in brain tissues. Also sleep deprivation of rats, which is a known treatment modality for depression, has been shown to increase the D-II activity (48). In contrast, lithium, carbamazepine, and fluoxetine have been shown to decrease the activity of the D-III enzyme $(44,46,47)$, also resulting in increased local $\mathrm{T}_{3}$ concentration (for overview, see Fig. 1). Although this is an attractive pattern, a contradictory study has demonstrated that lithium decreases the activity of D-II in mouse neural and pituitary tissues (49). One must also be aware that the above mentioned changes are not necessarily found in the same regions of the brain, and furthermore it is not known whether these regions have any relevance to depression.

The consequence of the effect of the antidepressive drugs on the D-II and D-III enzyme activities is an increased local $\mathrm{T}_{3}$ concentration in brain tissues and, as discussed above, this might increase local serotonin concentration, and thus might form an additional biological basis for the positive effect of these drugs in alleviating the depressive state.

Thus the hypothesis that a major pathogenic factor for depression is serotonin deficiency is sufficient to explain the changes seen in the HPT-axis. However, another hypothesis, put forward many years ago, has been that the depressed patient suffers a state of local hypothyroidism in the brain. This hypothesis, originally based on the similarities of symptoms seen in hypothyroidism and depression, seems supported by the finding that $\mathrm{T}_{3}$ treatment alleviated the depressive symptoms (50). Reduced $\mathrm{T}_{3}$ content in brain tissues leads to serotonin deficiency in brain tissues, and thus is sufficient to explain the findings in the HPT-axis seen in depression (Fig. 1).

Both hypotheses can explain that (i) patients with thyroid insufficiency are especially sensitive to develop depression $(51,52)$, (ii) $\mathrm{T}_{3}$ treatment is beneficial also in euthyroid, depressed patients, (iii) pharmacological stimulation of the D-II and inhibition of the D-III brain enzyme could be expected to have a beneficial effect on the depression, and (iv) $\mathrm{T}_{3}$ treatment might be at least as effective as $\mathrm{T}_{4}$ treatment. Only the serotonin deficiency hypothesis might explain the low normal serum TSH and low $\Delta$ max TSH seen during depression, and that patients with continued low $\Delta$ max TSH after apparent recovery from depression are subject to early relapse. This parameter can thus be regarded as a marker of continued active disease.

Another fruitful hypothesis developed for the biological explanation of depression suggested that depression was due to a state of relative brain deficiency of catecholamines, especially norepinephrine (53). This has formed the basis of the development of another group of useful antidepressive drugs, norepinephrine re-uptake inhibitors. In 1981 Whybrow \& Prange Jr (54) hypothesized that thyroid hormones, by enhancing beta-adrenergic receptor function, promote transmission in central noradrenergic pathways and accelerate recovery. Later, the same group (55) demonstrated that $\mathrm{T}_{3}$ levels in rat brain synaptosomes are much higher than whole brain levels, and that $\mathrm{T}_{3}$ but not $\mathrm{T}_{4}$ can be released from depolarized synaptosomes. Recently Rozanov \& Dratman (56) found increased $\mathrm{T}_{3}$ concentrations in nuclei and projection sites of rat central noradrenergic systems. These studies suggest that $\mathrm{T}_{3}$ may play a neuromodulatory or neurotransmitter role in the noradrenergic central nervous system. Norepinephrine stimulates the release of both TRH and TSH (23), and therefore norepinephrine deficiency cannot explain the changes in the HPT-axis seen in depression, especially the increased CSF TRH levels. However the hypothesis is fully compatible with the beneficial effect of $\mathrm{T}_{3}$ treatment in depression.

\section{Treatment of depression with hormones of the HPT-axis}

The similarities between symptoms seen in depression and untreated hypothyroidism have lead to several clinical trials in which thyroid hormones have been given to depressed patients, either alone or in combination with other antidepressive treatment modalities.

\section{Treatment without other treatment modalities}

TRH In the 1970s a number of studies demonstrated a mild but transient improvement in mood in depressed patients treated with TRH for a few days or at most 3 weeks. Later other studies including controlled doubleblind designs, failed to demonstrate any beneficial effect of TRH (reviewed in 57).

$\boldsymbol{T}_{3} \mathrm{~T}_{3}$ given as the only drug to depressed patients has been evaluated in only two studies. Feldmesser-Reiss (50) treated 24 patients with depression or melancholia with 10-15 $\mu \mathrm{g} \mathrm{T}_{3}$ daily, and observed considerable improvement in 10 patients. Wilson et al. (58) gave $25 \mu \mathrm{g}$, increasing to $62.5 \mu \mathrm{g}$, of $\mathrm{T}_{3}$ daily for 9 days to nine patients, which apparently was as effective on depression as imipramine, as evaluated by the Hamilton rating scale. Imipramine plus $\mathrm{T}_{3}$ had no additional effect. Unfortunately this otherwise randomized, double-blind study had no placebo group. Thus in 
these two studies $\mathrm{T}_{3}$ given alone seems to have an antidepressive effect, but placebo-controlled studies are lacking.

TSH and $\mathbf{T}_{4}$ We are not aware of any studies using TSH or $\mathrm{T}_{4}$ as the only treatment of depressed patients.

\section{Treatment in combination with other treatment modalities}

Several studies have evaluated the effect of the hormones of the HPT-axis. These studies can be separated into two typical designs: (i) either combination therapy with thyroid hormone and some kind of antidepressive treatment from the beginning, or (ii) adjunction of thyroid hormones to patients refractory to conventional antidepressive medication (nonresponders).

Initial combination therapy with $\mathrm{T}_{3}$ or TSH in depression Concerning the initial combination therapy, only the effect of $\mathrm{T}_{3}$ has been evaluated. Repeatedly in randomized, double-blind placebo-controlled studies, 20 to $50 \mu \mathrm{g} \mathrm{T}_{3}$ per day in combination with TCA has been shown to shorten the period of depression as compared with TCA alone (59-62), but the final number of recovered patients was not influenced (59, $60,62)$. However, in two other well-conducted trials, but with fewer patients, no additional effect of $\mathrm{T}_{3}$ with TCA could be demonstrated $(63,64)$. The studies demonstrating a beneficial effect of addition of $\mathrm{T}_{3}$ to TCA included in total 112 patients, whereas the two negative studies included only 29 patients. Furthermore the majority of patients studied were females.

The effect of $\mathrm{T}_{3}$ does not seem to be due to changed metabolism of TCA, and might thus be regarded as an independent factor (65).

Unfortunately no studies are available concerning the effect of the addition of $\mathrm{T}_{3}$ to the modern serotonin re-uptake inhibitory drugs.

In one study $\mathrm{T}_{3}$ or placebo was given to patients receiving ECT (66). Patients treated with $\mathrm{T}_{3}$ needed significantly fewer number of ECTs, and demonstrated less damage to memory functions, in comparison to the placebo group.

One study demonstrated a beneficial effect of TSH over placebo (in a randomized, double-blind fashion) when given to nine patients as intramuscular injections (10 units of TSH on day 1 and day 8) in adjunction to TCA (67). This study has unfortunately not been repeated, but it seems likely that the effect of TSH is due to an increased thyroidal secretion of $\mathrm{T}_{4}$ and $\mathrm{T}_{3}$.

$\mathrm{T}_{3}$ and $\mathrm{T}_{4}$ in refractory depression (nonresponders) $\mathrm{T}_{3}$ treatment of the depressed patient resistant to TCA was first reported beneficial in an open study without a placebo group (68). Since then the positive effect of 25$50 \mu \mathrm{g} \mathrm{T}_{3}$ daily as an adjunctive therapy has been confirmed in many studies, including a recent metaanalysis (69), which included four randomized doubleblind trials (in total 69 patients) and three unblinded studies using historical controls (in total 185 patients). This analysis also discussed in detail those studies which did not find any beneficial effect of $\mathrm{T}_{3}$. Overall the addition of $\mathrm{T}_{3}$ to TCA increased the response rate significantly from 24 to $57 \%$.

In another randomized double-blind study Joffe et al. (70) compared the ability of $\mathrm{T}_{3}$ and lithium to convert nonresponders to TCA into responders, i.e. reduce the depressive symptoms on a Hamilton Rating Scale. $\mathrm{T}_{3}$ was equally effective as lithium, and both drugs were superior to placebo.

No formal studies (only case reports) concerning the effect of the addition of $\mathrm{T}_{3}$ in depressed patients resistant to therapy with monoamine oxidase inhibitors or serotonin re-uptake inhibitors exist.

One study has compared the effect of physiological doses of $\mathrm{T}_{4}\left(150 \mu \mathrm{g}\right.$ daily) and $\mathrm{T}_{3}(37.5 \mu \mathrm{g}$ daily) as adjunctive therapy to nonresponders after 4 weeks on TCA. They found that $\mathrm{T}_{3}$ was more effective than $\mathrm{T}_{4}$ (71). Although randomized and double-blind, no placebo group was included, thus it is uncertain whether $\mathrm{T}_{4}$ is superior to placebo.

Interestingly, an open, uncontrolled trial on nine $\mathrm{L}-\mathrm{T}_{4}$-substituted hypothyroid patients (median $150 \mu \mathrm{g}$ daily) with depression and no response to TCA treatment, reported that seven of these patients recovered from depression after the addition of $\mathrm{T}_{3}$ (72), suggesting a decreased deiodination of $\mathrm{T}_{4}$ to $\mathrm{T}_{3}$ in brain.

In another open trial on six nonresponding patients (to TCA) with nonrapid cycling bipolar affective disorders, Baumgartner (73) gave supraphysiological doses of $\mathrm{T}_{4}(250-500 \mu \mathrm{g}$ daily) resulting in a reduced number of relapses. The results of this preliminary study are also compatible with a reduced deiodination of $\mathrm{T}_{4}$ to $\mathrm{T}_{3}$.

In the rapid cycling form of bipolar affective disorders, $\mathrm{T}_{4}$ adjunctive therapy has, in an open design without placebo controls (in total eight patients), been found to reduce both manic and depressive symptoms as well as number of relapses when given in supraphysiological doses (up to $500 \mu \mathrm{g}$ daily) $(74,75)$.

These studies are all compatible with an inhibition of the D-II deiodinase or a stimulation of the D-III deiodinase in brain tissues (resulting in a reduced local $\mathrm{T}_{3}$ concentration) in affective disorders.

\section{Antidepressive drugs - effect on thyroid hormones}

Changes in thyroid hormone and TSH levels during treatment of depressed patients with TCA and serotonin re-uptake inhibitors seem a result of the underlying psychiatric disorder, or its epiphenomena, i.e. increased 
serum cortisol and starvation, and not due to a direct effect of the drug on hormone secretion, plasma proteinbinding and turnover $(1,17,76)$.

In contrast lithium inhibits the secretion of thyroid hormones from the thyroid gland, resulting in an increase in serum $\operatorname{TSH}(77,78)$ and thyroid autoantibodies (79), which in susceptible patients might lead to overt hypothyroidism (79). This effect of lithium might result in a decreased supply of thyroid hormones to the brain, which according to the presented hypothesis is inconvenient. However the antidepressive effect of lithium has been demonstrated to be positively correlated to serum levels of $\mathrm{T}_{3}(80,81)$ and negatively to serum TSH levels (82). The effects of lithium on the deiodinases D-II and D-III with the result of local increase of $\mathrm{T}_{3}$ (see above) might counteract the inappropriate effect of lithium on the thyroid hormone secretion.

Carbamazepine, an anti-epileptic drug, which also has some antidepressive effect, influences the HPT-axis in a complex manner. In addition to the earlier mentioned effect on the brain deiodinases (Fig. 1), carbamazepine seems to enhance the hepatic (D-I) deiodination of both $\mathrm{T}_{4}$ and $\mathrm{T}_{3}(83)$. Thus these patients often present with low to normal serum levels of $\mathrm{T}_{4}$ and $\mathrm{T}_{3}$, but normal TSH levels (83), suggestive of some inhibitory effect on the thyrotrophs as well.

\section{Conclusions}

It is hypothesized that the changes seen in the HPT-axis in untreated depression might be explained partly by a cerebral serotonin deficiency. These changes tend to increase serum levels of $\mathrm{T}_{3}$, which subsequently might increase serotonin content in the brain. Although this hypothesis is attractive, it is based on few and small studies, which clearly need confirmation.

Subjects with thyroid insufficiency seem especially susceptible to the development of depression.

Well established antidepressive treatment modalities influence the brain deiodinases D-II and D-III, which are responsible for the local $\mathrm{T}_{3}$ production in brain tissues, in a manner leading to increased $\mathrm{T}_{3}$ concentrations. Defects of the brain deiodinases might be a pathogenic factor in depression.

While the effect of the addition of physiological doses of $\mathrm{T}_{3}$ to TCA is well documented in depression, confirmatory studies are needed concerning the effect of $\mathrm{T}_{3}$ given alone, and $\mathrm{T}_{3}$ given in addition to ECT.

In refractory depressions, the addition of $\mathrm{T}_{3}$ to TCA has been shown to be equal to the addition of lithium, and superior to the addition of placebo or $\mathrm{T}_{4}$, to TCA in alleviating depressive symptoms. The superiority of $\mathrm{T}_{3}$ compared with $\mathrm{T}_{4}$ as adjunctive therapy must be further evaluated.

No studies exist on the effect of $\mathrm{T}_{3}$ as adjunctive therapy to the serotonin re-uptake inhibitors, nor on the effect of $\mathrm{T}_{3}$ in rapid cycling depression.
The effects of thyroid hormones, TSH and TRH, on the depressive syndrome have been extensively studied during the past three decades. Despite the fact that many of these studies are more than 20 years old, many fulfill modern criteria of good clinical science, in terms of using the randomized, double-blind placebo-controlled design. Throughout this review, we have made efforts to describe the design of the studies cited. However, the potential weakness of these studies is the relatively small number of patients enrolled in the different treatment modalities. This is especially relevant, since the depressive syndrome is a heterogenous group of disorders affecting a large number of subjects; and furthermore the diagnostic criteria have changed over the years. Therefore previous findings should be re-evaluated, using modern scientific principles, and including a large number of patients. Furthermore, the effect of especially $\mathrm{T}_{3}$ in combination with various antidepressive treatment modalities (TCA, serotonin re-uptake inhibitors, ECT, sleep deprivation) should be studied.

The depressive syndrome is most likely a pathogenically heterogenous group. Patients are characterized phenomenologically, not by biological markers. Even phenomenologically identical groups might harbor different pathogenic subgroups of depression. Therefore future studies should also focus on identification of biological abnormalities in those patients who benefit from $\mathrm{T}_{3}$ treatment, in order to identify in which subgroups $\mathrm{T}_{3}$ treatment should be used.

In the light of the substantial amounts of data on the beneficial effect of $\mathrm{T}_{3}$ in depression, the restricted usage of $\mathrm{T}_{3}$ in this setting is surprising. $\mathrm{T}_{3}$ given in physiological doses is cheap and the monitoring is easy due to the new sensitive TSH assays. However, precautions should be taken in patients with concurrent heart disease, since $\mathrm{T}_{3}$ may sensitize the heart to the arrythmogenic effects of TCA. Suicidal patients especially seem to be exposed if they take overdoses of $\mathrm{T}_{3}$ and TCA in combination.

\section{References}

1 Kirkegaard C. The thyrotropin response to thyrotropin-releasing hormone in endogenous depression. Psychoneuroendocrinology 19816 189-212.

2 Baumgartner A, Gräf K-J, Kürten I \& Meinhold H. The hypothalamic-pituitary-thyroid axis in psychiatric patients and healthy subjects: Parts 1-4. Psychiatry Research $198824271-$ 332.

3 Kirkegaard C, Kørner A \& Faber J. Increased production of thyroxine and inappropriately elevated serum thyrotropin levels in endogenous depression. Biological Psychiatry $199027472-$ 476.

4 Faber J. The metabolism of iodothyronines in health and disease with special reference to diiodothyronines. Danish Medical Bulletin $198431257-270$.

5 Kirkegaard C \& Faber J. Free thyroxine and 3,3',5'-triiodothyronine levels in cerebrospinal fluid in patients with endogenous depression. Acta Endocrinologica 1991124 166-172.

6 Docter R, Krenning EP, de Jong M \& Hennemann G. The sick euthyroid syndrome: Changes in thyroid hormone serum 
parameters and hormone metabolism. Clinical Endocrinology $199339499-518$.

7 Ekins R. The free hormone hypothesis and measurement of free hormones. Clinical Chemistry 199238 1289-1293.

8 Faber J, Rogowski P, Kirkegaard C, Siersbæk-Nielsen K \& Friis T. Serum free $\mathrm{T}_{4}, \mathrm{~T}_{3}, \mathrm{rT}_{3}, 3,3^{\prime}$-diiodothyronine and $3^{\prime}, 5^{\prime}$-diiodothyronine measured by ultrafiltration. Acta Endocrinologica 1984107 $357-365$.

9 Kirkegaard C \& Faber J. Influence of free thyroid hormone levels on the TSH response to TRH in endogenous depression. Psychoneuroendocrinology 198611 491-497.

10 Faber J, Kirkegaard C, Jørgensen B \& Kludt J. The hidden, nonexchangeable pool of 3,5,3'-triiodothyronine and $3,3^{\prime}, 5^{\prime}$ triiodothyronine in man: does it exist? Acta Endocrinologica 1989 $120667-671$.

11 Kirkegaard C \& Faber J. Altered serum levels of thyroxine, triiodothyronines and diiodothyronines in endogenous depression. Acta Endocrinologica 198196 199-207.

12 Linnoila M, Cowdry R, Lamberg B-A, Makinen T \& Rubinow D. CSF triiodothyronine $\left(\mathrm{rT}_{3}\right)$ levels in patients with affective disorders. Biological Psychiatry 198318 1489-1492.

13 Maes M, Vandewoude M, Maes L, Schotte C \& Cosyns P. A revised interpretation of the TRH test results in female depressed patients. Journal of Affective Disorders 198916 203-213.

14 Duval F, Macher J-P \& Mokrani M-C. Difference between evening and morning thyrotropin response to protirelin in major depressive episode. Archives of General Psychiatry $199047443-$ 448 .

15 Maes M, Meltzer HY, Cosyns P, Suy E \& Schotte C. An evaluation of basal hypothalamic-pituitary-thyroid axis function in depression: Results of a large-scaled and controlled study. Psychoneuroendocrinology 199318 607-620.

16 Weeke A \& Weeke J. Disturbed circadian variation of serum thyrotropin in patients with endogenous depression. Acta Psychiatrica Scandinavica 197857 281-289.

17 Duval F, Mokrani M-C, Crocq M-A, Jautz M, Bailyy P, Diep T-S \& Macher J-P. Effect of antidepressant medication on morning and evening thyroid function tests during a major depressive episode. Archives of General Psychiatry 199653 833-840.

18 Kirkegaard C, Ølgaard K, Bliddal H, Faber J, Friis T \& SiersbækNielsen K. Different responses of serum TSH and $\mathrm{T}_{3}$ to oral TRH in various types of non-toxic goitre. Journal of Molecular Medicine $1980467-73$

19 Ylikorkala O, Kivinen S \& Kauppila A. Oral administration of TRH in puerperal women: Effect on insufficient lactation, thyroid hormones and on the responses of TSH and prolactin to intravenous TRH. Acta Endocrinologica 198093 413-418.

20 Kirkegaard C, Faber J, Hummer L \& Rogowski P. Increased levels of TRH in cerebrospinal fluid from patients with endogenous depression. Psychoneuroendocrinology 19794 227-235.

21 Banki CM, Bissette G, Arato M \& Nemeroff CB. Elevation of immunoreactive CSF TRH in depressed patients. American Journal of Psychiatry $19881451526-1531$.

22 Roy A, Wolkowitz OM, Bissette G \& Nemeroff CB. Differences in CSF concentrations of thyrotropin-releasing hormone in depressed patients and normal subjects: Negative findings. American Journal of Psychiatry 1994151 600-602.

23 Morley JE. Neuroendocrine control of thyrotropin secretion. Endocrine Review 19812 396-436.

24 Gerner RH \& Yamada T. Altered neuropeptide concentrations in cerebrospinal fluid of psychiatric patients. Brain Research 1982 238 298-302.

25 Post RM, Gold P, Rubinow DR, Ballenger JC, Bunney WE \& Goodwin FK. Peptides in the cerebrospinal fluid of neuropsychiatric patients: An approach to central nervous system peptide function. Life Sciences 198231 1-15.

26 Rubinow DR, Gold PW, Post RM, Ballenger JC, Cowdry R, Bollinger J \& Reichlin S. CSF somatostatin in affective illness. Archives of General Psychiatry 198340 377-386.
27 Gold MS, Pottash ALC \& Extein I. Hypothyroidism and depression: Evidence from complete thyroid evaluation. Journal of the American Medical Association 1981245 1919-1922.

28 Oomen HAPC, Schipperijn AJM \& Drexhage HA. The prevalence of affective disorder and in particular of rapid cycling of bipolar disorder in patients with abnormal thyroid function tests. Clinical Endocrinology 199645 215-223.

29 Howland RH. Thyroid dysfunction in refractory depression: Implications for pathophysiology and treatment. Journal of Clinical Psychiatry 1993 54 47-54.

30 Hickie I, Bennett B, Mitchell P, Wilhelm K \& Orlay W. Clinical and subclinical hypothyroidism in patients with chronic and treatment-resistant depression. Australian and New Zealand Journal of Physiology 199630 246-252.

31 Harris B, Othman S, Davies JA, Weppner GJ, Richards CJ, Newcombe RG, Lazarus JH, Parkes AB, Hall R \& Phillips DIW. Association between postpartum thyroid dysfunction and thyroid antibodies and depression. British Medical Journal $1992305152-$ 156.

32 Lazarus J, Harris B, Parkes A, Richards C \& Hall R. Postpartum thyroid disease (PPT) and depression - preliminary results of a randomized trial of thyroxine in prevention of psychiatric symptomatology. Journal of Endocrinological Investigation 1994 17 (Suppl 1) 26.

33 Krog-Meyer I, Kirkegaard C, Kijne B, Lumholtz B, Smith E, LykkeOlsen L \& Bjørum N. Prediction of relapse with the TRH test and prophylactic amitriptyline in 39 patients with endogenous depression. American Journal of Psychiatry $1984141945-948$.

34 Kvist J \& Kirkegaard C. Effect of repeated sleep deprivation on clinical symptoms and the TRH test in endogenous depression. Acta Psychiatrica Scandinavica 198062 494-502.

35 Prange Jr AJ, Wilson IC \& Lynn CW. L-Tryptophan in mania: Contribution to a permissive hypothesis of affective disorders. Archives of General Psychiatry 197430 56-62.

36 Sandrini M, Vitale G, Vergoni AV, Ottani A \& Bertolini A. Effect of acute and chronic treatment with triiodothyronine on serotonin levels and serotonergic receptor subtypes in the rat brain. Life Sciences 199658 1551-1559.

37 Upadhyaha L, Agrawal JK, Dubey GP \& Udupa KN. Biogenic amines and thyrotoxicosis. Acta Endocrinologica 1992126 315-318.

38 Cleare AJ, McGregor A \& O'Keane V. Neuroendocrine evidence for an association between hypothyroidism, reduced central 5-HT activity and depression. Clinical Endocrinology 199543 713-719.

39 Singhal RL, Rastogi RB \& Hrdina PD. Brain biogenic amines and altered thyroid function. Life Sciences 197517 1617-1626.

40 Rastogi RB \& Singhal RL. Influence of neonatal and adult hyperthyroidism on behavior and biosynthetic capacity for norepinephrine, dopamine and 5-hydroxytryptamine in rat brain. Journal of Pharmacology and Experimental Therapeutics $1976198609-618$.

41 Atterwill CK. Effect of acute and chronic tri-iodothyronine $\left(\mathrm{T}_{3}\right)$ administration to rats on central 5-HT and dopamine-mediated behavioural responses and related brain biochemistry. Neuropharmacology $198120131-144$.

42 Köhrle J, Hesch RD \& Leonard JL. Intracellular pathways of iodothyronines metabolism. In Werner and Ingbar's The Thyroid: A Fundamental and Clinical Text, edn 6, pp 144-189. Eds LE Braverman \& RD Utiger. Philadelphia: Lippincott, 1991.

43 Campos-Barros A, Hoell T, Musa A, Sampaolo S, Stoltenburg G, Pinna G, Eravci M, Meinhold H \& Baumgartner A. Phenolic and tyrosyl ring iodothyronine deiodination and thyroid hormone concentrations in the human central system. Journal of Clinical Endocrinology and Metabolism 199681 2179-2185.

44 Baumgartner A, Campos-Barros A, Gaio U, Hessenius C, Frege I \& Meinhold H. Effects of lithium on thyroid hormone metabolism in rat frontal cortex. Biological Psychiatry 199436 771-774.

45 Campos-Barros A, Meinhold H, Stula M, Müller F, Köhler R, Eravci M, Putzien O \& Baumgartner A. The influence of desimipramine on thyroid hormone metabolism in rat brain. Journal of Pharmacology and Experimental Therapeutics 1994268 1143-1152. 
46 Baumgartner A, Campos-Barros A, Gaio U, Hessenius C, Flechner A \& Meinhold H. Carbamazepine affects triiodothyronine production and metabolization in rat hippocampus. Life Sciences 199454 401-407.

47 Baumgartner A, Dubeyko M, Campos-Barros A, Eravci M \& Meinhold H. Subchronic administration on fluoxetine to rats affects triiodothyronine production and deiodination in regions of the cortex and in the limbic forebrain. Brain Research 1994635 $68-74$.

48 Campos-Barros A, Köhler R, Müller F, Eravci M, Meinhold H, Wesemann $W$ \& Baumgartner $A$. The influence of sleep deprivation on thyroid hormone metabolism in rat frontal cortex. Neuroscience Letters 1993162 145-148.

49 St Germain D. Regulatory effect of lithium on thyroxine metabolism in murine neural and anterior pituitary tissues. Endocrinology $19871201430-1436$.

50 Feldmesser-Reiss EE. The application of triiodothyronine in the treatment of mental disorders. Journal of Neurological and Mental Disorders 1958127 540-545.

51 Cowdry RW, Wehr TA, Zis AP \& Goodwin FK. Thyroid abnormalities associated with rapid-cycling bipolar illness. Archives of General Psychiatry $198340414-420$.

52 Bauer MS, Whybrow PC \& Winokur A. Rapid cycling bipolar affective disorder. Archives of General Psychiatry $199047427-$ 432 .

53 Schildkraut JJ. The catecholamine hypothesis of affective disorders: A review of supporting evidence. American Journal of Psychiatry 1965122 509-522.

54 Whybrow PC \& Prange Jr AJ. A hypothesis of thyroidcatecholamine-receptor interaction. Archives of General Psychiatry 198138 106-113.

55 Mason GA, Walker CH \& Prange Jr AJ. L-Triiodothyronine: Is this peripheral hormone a central neurotransmitter? Neuropsychopharmacology 19938 253-258.

56 Rozanov CB \& Dratman MB. Immunohistochemical mapping of brain triiodothyronine reveals prominent localization in central noradrenergic systems. Neuroscience 199674 897-915.

57 Stein D \& Avni J. Thyroid hormones in the treatment of affective disorders. Acta Psychiatrica Scandinavica 198877 623-636.

58 Wilson IC, Prange Jr AJ \& Lara PP. L-Triiodothyronine alone and with imipramine in the treatment of depressed women. In The Thyroid Axis, Drugs, and Behavior, pp 49-62. Ed AJ Prange Jr. New York: Raven Press, 1974.

59 Prange Jr AJ, Wilson IC, Rabon AM \& Lipton MA. Enhancement of imipramine antidepressant activity by thyroid hormone. American Journal of Psychiatry 1969126 457-469.

60 Wilson IC, Prange Jr AJ, McClane TK, Rabon AM \& Lipton MA Thyroid hormone enhancement of imipramine in nonretarded depressions. New England Journal of Medicine $19702821063-$ 1067.

61 Coppen A, Whyborw PC, Noguera R, Maggs R \& Prange Jr AJ. The comparative antidepressant value of L-tryptophan and imipramine with and without attempted potentiation by liothyronine. Archives of General Psychiatry 197226 234-241.

62 Wheatley D. Potentiation of amitriptyline by thyroid hormone. Archives of General Psychiatry 197226 229-233.

63 Feighner JP, King LJ, Schuckit MA, Croughan J \& Briscoe W. Hormonal potentiation of imipramine and ECT in primary depression. American Journal of Psychiatry 1972128 1230-1238.

64 Steiner M, Radwan M, Elizur A, Blum I, Atsmon A \& Davidson S. Failure of L-triiodothyronine $\left(\mathrm{T}_{3}\right)$ to potentiate tricyclic antidepressant response. Current Therapeutic Research 197823 655-659.

65 Garbutt J, Malekpour B, Brunswik D, Jonnalagadda MR, Jolliff L, Podolak R, Wilson I \& Prange Jr AJ. Effects of triiodothyronine on drug levels and cardiac function in depressed patients treated with imipramine. American Journal of Psychiatry 1979136 980-983.
66 Stern RA, Nevels CT, Shelhorse ME, Prohaska ML, Mason GA \& Prange Jr AJ. Antidepressant and memory effects of combined thyroid hormone treatment and electroconvulsive therapy: Preliminary findings. Biological Psychiatry 199130 623-627.

67 Prange Jr AJ, Wilson IC, Knox A, McClane TK \& Lipton MA. Enhancement of imipramine by thyroid stimulating hormone: Clinical and theoretical implications. American Journal of Psychiatry 1970127 191-199.

68 Earle B. Thyroid hormone and tricyclic antidepressants in resistant depressions. American Journal of Psychiatry 1970126 1667-1669.

69 Aronsen R, Offman HJ, Joffe RT \& Naylor CD. Triiodothyronine augmentation in the treatment of refractory depression. Archives of General Psychiatry 199653 842-848.

70 Joffe RT, Singer W, Levitt AJ \& MacDonald C. A placebo-controlled comparison of lithium and triiodothyronine augmentation of tricyclic antidepressants in unipolar refractory depression. Archives of General Psychiatry 199350 387-393.

71 Joffe RT \& Singer W. A comparison of triiodothyronine and thyroxine in the potentiation of tricyclic antidepressants. Psychiatry Research 199032 241-251.

72 Cooke RG, Joffe RT \& Levitt AJ. T 3 augmentation of antidepressant treatment in $\mathrm{T}_{4}$-replaced thyroid patients. Journal of Clinical Psychiatry 199253 16-18.

73 Baumgartner A, Bauer M \& Hellweg R. Treatment of intractable non-rapid cycling bipolar affective disorder with high-dose thyroxine: An open trial. Neuropsychopharmacology 199410 183-189.

74 Stancer HC \& Persad E. Treatment of intractable rapid-cycling manic-depressive disorder with levothyroxine. Archives of General Psychiatry 198239 311-312.

75 Bauer MS \& Whybrow PC. The effect of changing thyroid function on cyclic affective illness in a human subject. American Journal of Psychiatry 1986143 633-636.

76 Linnolia M, Gold P, Potter WZ \& Wehr TA. Tricyclic antidepressants do not alter thyroid hormones levels in patients suffering from a major affective disorder. Psychiatry Research $19814357-360$.

77 Emerson $\mathrm{CH}$, Dyson WL \& Utiger RD. Serum thyrotropin and thyroxine concentrations in patients receiving lithium carbonate. Journal of Clinical Endocrinology and Metabolism 197336 338-346.

78 Lauridsen UB, Kirkegaard C \& Nerup J. Lithium and the pituitarythyroid axis in normal subjects. Journal of Clinical Endocrinology and Metabolism 197439 383-385.

79 Myers DH, Carter RA, Burns BH, Armond A, Hussain SB \& Chengapa VK. A prospective study of the effects of lithium on thyroid function and on the prevalence of antithyroid antibodies. Psychological Medicine 198515 55-61.

80 Hatterer JA, Kocsis JH \& Stokes PE. Thyroid function in patients maintained on lithium. Psychiatry Research 198826 249-257.

81 Baumgartner A, von Stuckrad M, Müller-Oerlinghausen B, Gräf K-J \& Kürten I. The hypothalamic-pituitary-thyroid axis in patients maintained on lithium prophylaxis for years: High triiodothyronine serum concentrations are correlated to the prophylactic efficacy. Journal of Affective Disorders 199534 211-218.

82 Prohaska ML, Stern RA, Nevels CT, Mason GA \& Prange Jr AJ. The relationship between thyroid status and neuropsychological performance in psychiatric outpatients maintained on lithium. Neuropsychiatry Neuropsychology and Behavioral Neurology 19969 30-34.

83 Wenzel KW. Disturbances of thyroid function tests by drugs. Acta Medica Austriaca 199623 57-60.

Received 27 February 1997

Accepted 14 July 1997 